\title{
Correction to: Comparison of hip subregion bone mineral density to the type of proximal femur fracture
}

\author{
Yongun $\mathrm{Cho}^{1}$ (D) Ingyu Lee ${ }^{2}$ (D) Sang Hoon Ha ${ }^{2}$ (D) Jin Hun Park ${ }^{2}$ (D) Jai Hyung Park ${ }^{2}$ (D) \\ Published online: 8 September 2020 \\ (C) International Osteoporosis Foundation and National Osteoporosis Foundation 2020
}

\section{Correction to: Archives of Osteoporosis (2020) 15:122} https://doi.org/10.1007/s11657-020-00789-2

The original version of this article, published on 05 August 2020, unfortunately contained a mistake.

The correct version of the last sentence in the Abstract under the Methods section is given below.
We did multiple linear regression analysis among these parameters.

Publisher's note Springer Nature remains neutral with regard to jurisdictional claims in published maps and institutional affiliations. 